\title{
Neuroma prevalence and neuroma-associated factors in patients with traumatic lower extremity amputation
}

\author{
(1) Merve Örücü Atar, (1) Yasin Demir, (1) Gizem Kılınç Kamacı, (1) Nurdan Korkmaz, (1) Sefa Gümrük Aslan, \\ (1) Koray Aydemir
}

Gaziler Physical Medicine and Rehabilitation Training and Research Hospital, Clinic of Physical Medicine and Rehabilitation, Ankara, Turkey

Date submitted:

16.01.2021

Date accepted:

17.03.2021

Online publication date: 15.03.2022

\section{Corresponding Author:}

Merve Örücü Atar, M.D., Gaziler

Physical Medicine and Rehabilitation

Training and Research Hospital,

Clinic of Physical Medicine and

Rehabilitation, Ankara, Turkey

drmerveorucu@hotmail.com

ORCID:

orcid.org/0000-0002-6439-8818

Keywords: Amputation, neuroma, pain, ultrasound, radiography

\begin{abstract}
Aims: There is limited understanding of factors related to the development of symptomatic neuromas. The aims of this study were to determine the prevalence of neuroma in amputees with residual limb pain (RLP) and to examine factors associated with neuromas.

Methods: A retrospective and cross-sectional study was conducted at the amputee rehabilitation unit of a tertiary hospital in Turkey. Demographic, clinical, ultrasonographic and radiographic records between September 2016 and April 2020 were evaluated. Bone anatomy in the affected limb was evaluated by radiographic examination. Both neuroma site and size were evaluated with ultrasonography.
\end{abstract}

Results: A total of 85 patients (107 amputations) were included in the study. Neuroma was detected in $47.1 \%$ of the patients with RLP. Sixty percent of the patients with neuroma had a duration of longer than 5 years since amputation. The most common amputation level was transtibial (below-the-knee, 61.9\%). Neuroma was more frequently identified in patients with landmine injury $(57.5 \%)$ than without $(37.8 \%)$. A correlation was found between the time after amputation and the neuroma size $(r=0.47, p=0.001)$. There was no correlation between visual analog scale scores and neuroma size $(r=-0.09, p=0.570)$. There was also no relationship between bone spurs and neuromas.

Conclusions: Half of lower limb amputees with RLP were found to have neuromas. Clinicians should be aware of the high prevalence of neuroma among the causes of RLP to manage the rehabilitation procedure of these patients appropriately.

\section{Introduction}

About 185.000 upper or lower limb amputations are done annually (1). Limb amputations caused by trauma and diseases is a devastating condition and causes psychological and functional disabilities $(2,3)$. Residual limb pain (RLP), defined as pain felt in the rest of the amputated limb, is one of the chronic complications of amputations (1). Neuromas, the tumor-like thickening of a nerve stump in the scar area after amputation of a limb sensitive to pressure are among the causes of RLP (4). Patients with neuroma usually describe the pain as intense paroxysmal burning pain or low-intensity dull pain, often provoked by external stimuli like temperature and touch. The diagnosis of symptomatic neuromas can be made with the medical history, response to a diagnostic proximal nerve block, physical symptoms, the Tinel sign, and imaging (5).

Both magnetic resonance imaging (MRI) and ultrasonography (US) are useful to detect the suspected neuromas $(6,7)$. While $\mathrm{MRI}$ is expensive and not widely available, US is inexpensive, commonly available, and cheaper (8). The classic appearance of the neuroma, which may be well-circumscribed or have irregular margins, is hypoechoic, oval mass in direct contiguity with the nerve $(7,9)$.

The prevalence of symptomatic neuroma in patients with extremity amputation varies extensively, and there is uncertainty about their actual prevalence in the literature (5). There is also a limited understanding of the factors related to the development of 
symptomatic neuromas. Landmine injury, nerve trunk indentation of bone spurs, and central pain phenomenon may be associated with neuroma development (10-13). Nonetheless, there are limited studies on the association of the aforementioned factors with neuroma. Examining the factors that cause stump neuroma formation and the features of neuroma may help develop new rehabilitative strategies for the prevention and management of neuroma in patients with amputation.

This study aimed to determine the prevalence of neuroma in amputees with RLP and to examine the potential factors associated with neuromas.

\section{Methods}

A retrospective and cross-sectional study was conducted. The study population consisted of patients with traumatic lower extremity amputation referred to the Amputee Rehabilitation Unit of a tertiary hospital, between September 2016 and April 2020 (Ankara Gaziler Physical Medicine and Rehabilitation Training and Research Hospital). Patients with RLP between the ages of 18-65 years were included in the study. The exclusion criteria were age over 65 years, partial foot or toe loss, congenital limb deficiency, phantom limb pain, nontraumatic etiology, absence of radiographic view, and the absence of stump US record. The study protocol was approved by the Committee on Human Research Ethics at Ankara City Hospital (Nr.: E1-20-839, date: 25.06.2020).

Each amputation was considered an individual case in patients with more than one amputation. Age, gender, height, weight, comorbidities, amputation type, time since amputation, amputation level, amputation etiology, US findings, and radiological findings were obtained from the medical records. Bone anatomy in the affected limb was evaluated by radiographic examination and spur formation was recorded if any. The perception of pain by the patient was evaluated using the visual analog scale (VAS) (0-10 points) at initial admission [VAS; from 0 (no pain) to 10 (worst pain)].

All sonographic evaluations were performed by a radiologist experienced in musculoskeletal sonography. Both neuroma site and size were identified using US imaging. The size of each neuroma in the amputation stump was measured along two axes (Figure 1). If there was more than one neuroma in an amputation stump, the size of the largest neuroma was recorded. Mainly three types of neuroma associated with RLP have been identified: 1) fusiform/lobulated shaped neuroma formed of a radiating network of tiny nerves, 2) cylindrical-shaped neuroma, 3 ) neuroma that keeps the morphology of a normal but swollen nerve (10).

We hypothesized that neuroma sizes may differ depending on the duration of the disease. Therefore, patients were divided into 3 groups according to the duration after amputation $(<1$ year, 1-5 years, and $>5$ years).

\section{Statistical Analysis}

The Statistical Package for the Social Sciences Statistics for Windows (version 23.0, Armonk, NY: IBM Corp., 2015) was used for statistical analysis. Continuous variables were expressed as mean and standard deviation (SD) or minimum-maximum values. Categorical variables were presented in frequency (\%). Student's t-test and Mann-Whitney $U$ tests were used for comparison of mean values between groups. The chi-square test was used for frequency comparisons. Spearman or Pearson coefficient used for correlation analysis. One-way ANOVA was used to compare neuroma sizes among the amputation year $(<1$ years / 1 to 5 years / >5 years) groups. Statistical significance was set at $p<0.05$.

\section{Results}

A total of 85 patients (107 amputations) were included in the study (Figure 2). All patients were male (100\%). Fortytwo neuromas were identified in total (39.3\%). Neuroma was detected in $47.05 \%$ of the patients with RLP.

Patients with neuroma were aged between 22 and 53 years (mean $\pm S D, 35.8 \pm 8.6$ years). The mean time since amputation was $131.2 \pm 110.5$ months (range, 4-360 months) and $60 \%$ of the patients had a duration of longer than 5 years. Neuroma was identified more frequently in patients with landmine injury $(57.5 \%)$ than without $(37.8 \%)$ but the difference did not reach statistical significance $(p=0.070)$. The most common level of amputation was transtibial (below-the-knee, 61.9\%). The VAS scores ranged from 2 to 10 points (mean $\pm S D, 7.0 \pm 2.2$ ). Demographic variables were not significantly different between patients with and without neuroma as shown in Table 1.

Neuroma formation was the most common in the posterior part of the amputation stump (53.1\%) (Figure 3). The neuroma

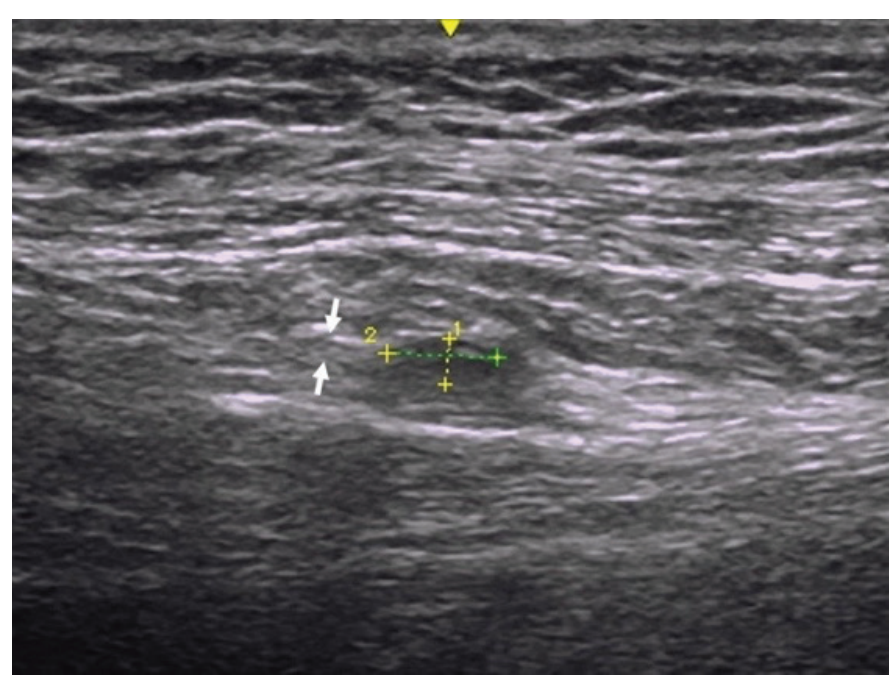

Figure 1. A longitudinal ultrasound image shows ovoid, hypoechoic lesion representing a neuroma in the amputation stump, directly continuous to femoral nerve (arrow) 
208 patients with limb loss determined by amputee database from 2016 to 2020

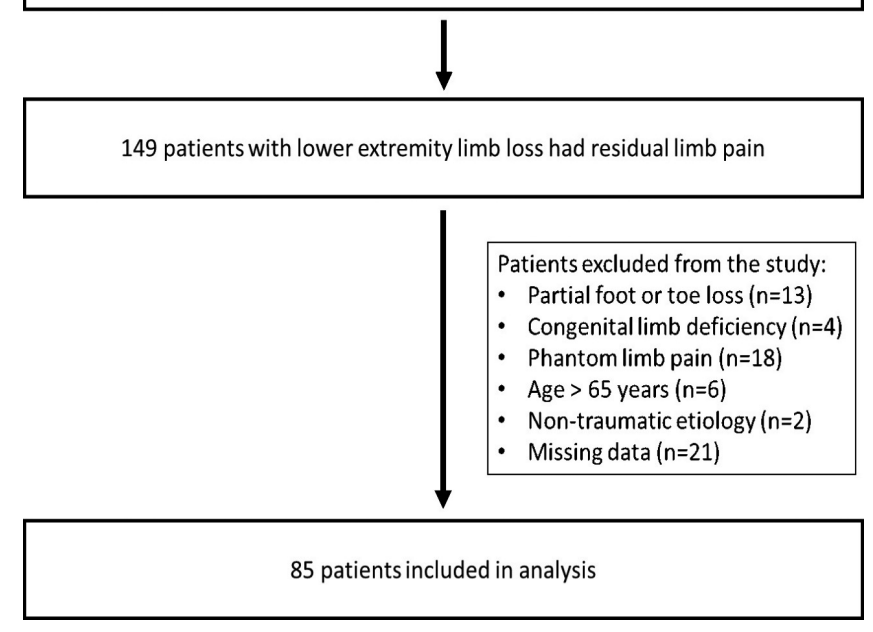

Figure 2. Flow chart of the study size ranged from $9.4 \mathrm{~mm}^{2}$ to $320.3 \mathrm{~mm}^{2}$ (mean \pm SD, $76.8 \pm 64.3$ $\mathrm{mm}^{2}$ ). When the neuroma size was compared according to the amputation year, a statistically significant difference was found

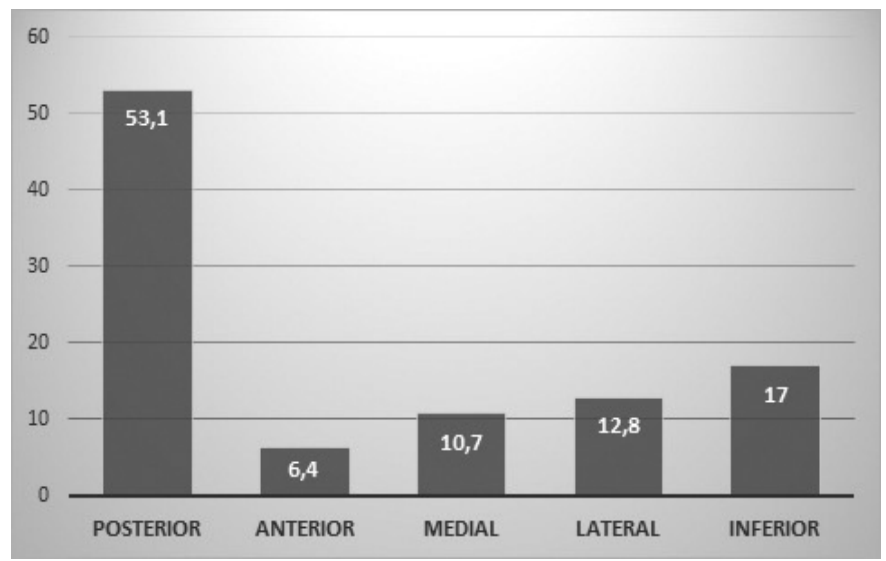

Figure 3. Distribution of neuroma sites in amputation stump

\begin{tabular}{|c|c|c|c|}
\hline Variable & Neuroma (+) $(n=40)$ & Neuroma $(-)(n=45)$ & p \\
\hline Age (years), mean $\pm S D$ & $35.8 \pm 8.6$ & $34.3 \pm 8.5$ & 0.460 \\
\hline BMI, mean $\pm S D$ & $26.0 \pm 4.1$ & $25.0 \pm 3.5$ & 0.270 \\
\hline \multicolumn{4}{|l|}{ Comorbidities, n (\%) } \\
\hline Hypertension & $2(5)$ & $4(8.9)$ & 0.480 \\
\hline Diabetes mellitus & $1(2.5)$ & $3(6.7)$ & 0.360 \\
\hline Time since amputation (months), mean \pm SD & $131.2 \pm 110.5$ & $106.2 \pm 102.1$ & 0.420 \\
\hline Time since amputation (years), n (\%) & & & 0.110 \\
\hline$<1$ year & $11(27.5)$ & $9(20)$ & \\
\hline $1-5$ years & $5(12.5)$ & $14(31.1)$ & \\
\hline$>5$ years & $24(60)$ & $22(48.9)$ & \\
\hline Etiology, n (\%) & & & 0.310 \\
\hline Mine & $23(57.5)$ & $17(37.8)$ & \\
\hline Explosives & $7(17.5)$ & $13(28.9)$ & \\
\hline Gunshot & $7(17.5)$ & $6(13.3)$ & \\
\hline Rocket & $2(5)$ & $4(8.9)$ & \\
\hline Electrical injury & $1(2.5)$ & $4(8.9)$ & \\
\hline Car accident & 0 & $1(2.2)$ & \\
\hline Amputation side, $\mathrm{n}(\%)$ & & & 0.530 \\
\hline Right & $16(40.0)$ & $13(28.9)$ & \\
\hline Left & $14(35)$ & $20(44.4)$ & \\
\hline Bilateral & $10(25)$ & $12(26.7)$ & \\
\hline Amputation level, $\mathrm{n}(\%)$ & & & 0.180 \\
\hline Total & $42(39.3)$ & $65(60.7)$ & \\
\hline Hip & $0(0.0)$ & $1(1.5)$ & \\
\hline Above-the-knee & $14(33.3)$ & $28(43.1)$ & \\
\hline Knee & $2(4.8)$ & $2(3.1)$ & \\
\hline Below-the-knee & $26(61.9)$ & $29(44.6)$ & \\
\hline Ankle (Syme) & 0 & $5(7.7)$ & \\
\hline
\end{tabular}


between the groups ( $>1$ year, $1-5$ years, $>5$ years) $(p=0.010)$. The size of the neuroma was significantly larger in the group with amputation time over 5 years compared to the group under 1 year $(p=0.030)$. There was no statistically significant difference in the size of the neuroma between the group with amputation time of 1-5 years and the groups with amputation time below 1 year and above 5 years $(p=0.980, p=0.100$, respectively) (Table 2).

A correlation was found between the time after amputation and the size of the neuroma $(r=0.47, p=0.001)$. There was no correlation between VAS scores and neuroma size $(r=-0.09$, $p=0.570$ ) as shown in Table 3.

In patients with a neuroma, radiographic imaging revealed femoral spur in $35.7 \%$ of transfemoral amputations, tibial spur in $29.2 \%$, and fibular spur in $37.5 \%$ of the transtibial amputations. In patients without neuroma, on the other hand, radiographic imaging revealed femoral spur in $35.7 \%$ of transfemoral amputations, tibial spur in $14.3 \%$, and fibular spur in $28.6 \%$ of the transtibial amputations. There was no statistically significant difference in the frequency of bone spurs between patients with and without neuroma ( $p=0.930, p=0.190, p=0.490$, respectively). There was no relationship between bone spurs and neuromas.

\section{Discussion}

The development of amputation stump neuromas is a frequent and common cause of stump pain that results from compression of the sensitive nerve endings by adjacent soft tissues (14), nerve traction by scar tissue surrounding and fixing the neuroma (15), or decreased blood supply to the neuroma with hypoxia of the nerve endings (16).

There is uncertainty about the actual prevalence rate of symptomatic neuroma in the literature, ranging from $4 \%$ to $49 \%$ (5). Neuroma was detected in $47.1 \%$ of the patients with RLP in our study. This relatively higher prevalence compared to most of the previous reports may be associated with the small sample size and retrospective design of the study.
The most common level of amputation was transtibial by $61.9 \%$ in patients with a neuroma in our study. A difference in terms of biomechanical load on the stump has been stated between transtibial amputees and others (17). Moreover, patients with transtibial amputations are more functional and mobile than individuals with upper amputation levels (18). Therefore, increased mechanical forces may affect the formation of neuroma in individuals with transtibial amputation (10).

RLP is an important problem in patients with landmine injury $(19,20)$. We found that neuroma was identified in $57.5 \%$ of patients with landmine injury. Similarly, neuroma was detected in half of the patients with landmine injury in a study by Aydemir et al. (10). It has been reported that unshaped stump, non-elective sudden surgery, and contaminated blast-related extremity wound affect the development of stump neuromas in patients with landmine injury $(4,21)$.

Neuromas develop within a 1-12-month period following a traumatic event or a nerve transection. The size of neuroma increases due to localized chronic irritation and is affected by the immediate environment, especially in areas where pressure is bearing. The slow growth of the neuroma is noticed over 2-3 years (13), after that growth ceases. However, neuromas remain in situ for the patient's lifetime. The enlargement of the neuroma is limited, and its final size is directly associated with the number of damaged axons (22) and the size of the main nerve (13). In our study, a correlation was also found between the time after amputation and the size of the neuroma; however, there was no correlation between pain scores and neuroma size. Similarly, there was no relationship between pain scores and neuroma volume in a study by O'Reilly et al. (11).

The time from the first injury to present neuromas is quite variable. Neuromas can be asymptomatic for a long time. In our study, neuroma after 5 years of amputation in $60 \%$ of the patients suggests that RLP caused by symptomatic neuromas may have a late-onset. Therefore, long-term follow-up is required for

\begin{tabular}{lllll}
\hline \multicolumn{4}{l}{ Table 2. Time since amputation, amputation type, and mean area of neuromas } & \\
\hline Time since amputation & Above-knee & Knee & Below-knee & Area of neuroma, $\mathbf{m m}^{\mathbf{2}} \mathbf{m e a n} \pm \mathbf{S D}$ \\
\hline$<1$ year & 2 & 1 & 7 & $41.32 \pm 30.45$ \\
\hline $1-5$ years & 3 & 0 & 4 & $46.65 \pm 27.35$ \\
\hline$>5$ years & 9 & 1 & 15 & $99.41 \pm 72.20$ \\
\hline
\end{tabular}

Table 3. Correlations between neuroma size and demographic and clinical parameters of patients

\begin{tabular}{lll} 
& Neuroma size $\left(\mathbf{m m}^{2}\right)$ & p \\
\cline { 2 - 3 } & $\mathbf{r}$ & $0.029^{*}$ \\
\hline Age, years & 0.346 & 0.062 \\
\hline Body mass index, $\mathrm{kg} / \mathrm{m}^{2}$ & 0.758 & $0.001^{*}$ \\
\hline Time since amputation, months & 0.471 & 0.574 \\
\hline Visual analogue scale & -0.091 & \\
\hline
\end{tabular}


patients with lower extremity amputation due to probable lateonset of RLP caused by neuromas (5).

Altered anatomy because of amputation can probably cause the development of many bone lesions including bone spurs (11). It has been declared that nerve trunk indentation of bone spurs can be associated with neuromas (23). In the US imaging study by O'Reilly et al. (11), it was reported that some symptomatic neuromas appear to be attached to the cut end of the bone or bony spur or the periosteum or the scar. Prompt shaving of bone surfaces is recommended during amputation surgery (23). There was no relationship between bone spurs and neuromas in our study. Further prospective studies are needed to investigate the relationship between the bone cutting technique and bony spurs and neuroma formation.

This study has several limitations. First, the sample size in the study is overall small. Second, the results of the study are limited to patients with lower limb amputations, not reflecting patients with upper limb amputations. Third, the morphology of the nerves has not been evaluated in the study. Since the evaluation of the morphology of the nerves may allow for a more detailed analysis of the formation of a neuroma. Last, it is stated in which part of the stump the neuroma is detected, but it is not specified in which nerve the neuroma is related.

\section{Conclusion}

In conclusion, this study found a high prevalence of symptomatic neuroma among lower limb amputees. The frequency of neuromas was higher in patients with transtibial amputation and landmine injury. There was no relationship between bone spurs and neuromas. The period after amputation for more than half of the patients with neuroma was a minimum of 5 years. Although there was a correlation between the amputation time and the neuroma size, there was no correlation between pain scores and neuroma size.

\section{Ethics}

Ethics Committee Approval: The study protocol was approved by the Committee on Human Research Ethics at Ankara City Hospital (no: E1-20-839, date: 25.06.2020).

Informed Consent: Retrospective and cross-sectional study.

Peer-review: Externally peer-reviewed.

\section{Authorship Contributions}

Concept: M.Ö.A., Design: M.Ö.A., Data Collection or Processing: M.Ö.A., G.K.K., Analysis or Interpretation: M.Ö.A., Y.D., K.A., Literature Search: S.G.A., Writing: M.Ö.A., Y.D., N.K., S.G.A., K.A.

Conflict of Interest: No conflict of interest was declared by the authors.
Financial Disclosure: The authors declared that this study received no financial support.

\section{References}

1. Hsu E, Cohen SP. Postamputation pain: epidemiology, mechanisms, and treatment. J Pain Res. 2013;6:121-136.

2. Horgan $\mathrm{O}$, MacLachlan M. Psychosocial adjustment to lowerlimb amputation: a review. Disabil Rehabil. 2004;26:837-850.

3. Hisam A, Ashraf F, Rana MN, Waqar Y, Karim S, Irfan F. Health Related Quality of Life in Patients with Single Lower Limb Amputation. J Coll Physicians Surg Pak. 2016;26:851-854.

4. Sehirlioglu A, Ozturk C, Yazicioglu K, Tugcu I, Yilmaz B, Goktepe AS. Painful neuroma requiring surgical excision after lower limb amputation caused by landmine explosions. Int Orthop. 2009;33:533-536.

5. List EB, Krijgh DD, Martin E, Coert JH. Prevalence of residual limb pain and symptomatic neuromas after lower extremity amputation: a systematic review and meta-analysis. Pain. 2021;162:1906-1913.

6. Singson RD, Feldman F, Staron R, Fechtner D, Gonzalez E, Stein J. MRI of postamputation neuromas. Skeletal Radiol. 1990;19:259-262.

7. Provost N, Bonaldi VM, Sarazin L, Cho KH, Chhem RK. Amputation stump neuroma: ultrasound features. J Clin Ultrasound. 1997;25:85-89.

8. Zanetti M, Hodler J. [Sonography of the musculoskeletal system]. Ther Umsch. 1997;54:18-23.

9. Henrot P, Stines J, Walter F, Martinet N, Paysant J, Blum A. Imaging of the painful lower limb stump. Radiographics. 2000;20(Suppl):219-235.

10. Aydemir K, Demir Y, Güzelküçük U, Tezel K, Yilmaz B. Ultrasound Findings of Young and Traumatic Amputees With Lower Extremity Residual Limb Pain in Turkey. Am J Phys Med Rehabil. 2017;96:572-577.

11. O'Reilly MA, O'Reilly PM, O'Reilly HM, Sullivan J, Sheahan J. High-resolution ultrasound findings in the symptomatic residual limbs of amputees. Mil Med. 2013;178:1291-1297.

12. Penna A, Konstantatos AH, Cranwell W, Paul E, BruscinoRaiola FR. Incidence and associations of painful neuroma in a contemporary cohort of lower-limb amputees. ANZ J Surg. 2018;88:491-496.

13. Singson RD, Feldman F, Slipman CW, Gonzalez E, Rosenberg ZS, Kiernan H. Postamputation neuromas and other symptomatic stump abnormalities: detection with CT. Radiology. 1987;162:743-745.

14. Fisher GT, Boswick JA Jr. Neuroma formation following digital amputations. J Trauma. 1983;23:136-142.

15. Thomas AJ, Bull MJ, Howard AC, Saleh M. Peri operative ultrasound guided needle localisation of amputation stump neuroma. Injury. 1999;30:689-691.

16. Mathews GJ, Osterholm JL. Painful traumatic neuromas. Surg Clin North Am. 1972;52:1313-1324.

17. Jones SF, Twigg PC, Scally AJ, Buckley JG. The mechanics of landing when stepping down in unilateral lower-limb amputees. Clin Biomech (Bristol, Avon) 2006;21:184-193. 
18. Serizawa F, Sasaki S, Fujishima S, Akamatsu D, Goto H, Amada N. Mortality rates and walking ability transition after lower limb major amputation in hemodialysis patients. J Vasc Surg. 2016;64:1018-1025.

19. Rathore FA, Ayaz SB, Mansoor SN, Qureshi AR, Fahim M. Demographics of Lower Limb Amputations in the Pakistan Military: A Single Center, Three-Year Prospective Survey. Cureus. 2016;8:e566.

20. Fergason J, Keeling JJ, Bluman EM. Recent advances in lower extremity amputations and prosthetics for the combat injured patient. Foot Ankle Clin. 2010;15:151-174.
21. Necmioglu S, Subasi M, Kayikci C, Young DB. Lower limb landmine injuries. Prosthet Orthot Int. 2004;28:37-43.

22. Murphey MD, Smith WS, Smith SE, Kransdorf MJ, Temple HT. From the archives of the AFIP. Imaging of musculoskeletal neurogenic tumors: radiologic-pathologic correlation. Radiographics. 1999;19:1253-1280.

23. Kömürcü E, Ozçakar L, Safaz I, Göktepe AS. A common peroneal neuroma due to a bony spur in a lower-limb amputee: a sonographic diagnosis. Am J Phys Med Rehabil. 2010;89:434-435. 